\title{
Electrochemical Studies of Sulfur Dioxide Absorption and Desorption in Ionic Liquids
}

\author{
Xuyan Mao ${ }^{1, *}$, Maocheng $\mathrm{Wu}^{2}$, Xiangyu $\mathrm{Xu}^{1}$, Liang Jiang${ }^{1}$, Jie Yang ${ }^{1}$, Zhongyu $\mathrm{Du}^{3}$, Jianjun \\ $\mathbf{L i}^{3}$, Yuanyuan Zhang ${ }^{4}$ \\ ${ }^{1}$ Bio-nano \& Medical Engineering Institute, Jining Medical University, Jining, Shandong, China \\ ${ }^{2}$ Shelile Research and Development centers, Shandong LuKang Shelile Pharmaceutical Co. ltd, Jining, \\ Shandong, China \\ ${ }^{3}$ Jining Medical University, Jining, Shandong, China \\ ${ }^{4}$ Testing Laboratory, Shandong Huaheng Material Testing Co., Ltd, Jining, Shandong, China \\ *corresponding author: xuyanm_06@163.com
}

Keywords: Electrochemical sensor; $\mathrm{SO}_{2}$; Ionic liquids; $\mathrm{MoS}_{2}$.

\begin{abstract}
To improve the efficiency of the detection of $\mathrm{SO}_{2}$, we propose a method using $[$ Bmim $]\left[\mathrm{Tf}_{2} \mathrm{~N}\right]$. Under normal atmospheric pressure, the $[\mathrm{Bmim}]\left[\mathrm{Tf}_{2} \mathrm{~N}\right]$ has a good effect for absorbing $\mathrm{SO}_{2}$. The $[\mathrm{Bmim}]\left[\mathrm{Tf}_{2} \mathrm{~N}\right]$ was directly used as an electrolyte to measure the $\mathrm{SO}_{2}$ absorption rate and good results were obtained. By comparing the redox reactions of $\mathrm{SO}_{2}$ with three kinds of electrodes, it was found that the reaction current was the highest, indicating that $\mathrm{MoS}_{2}$ has better electrochemical properties. This method was applied to the absorption and detection of $\mathrm{SO}_{2}$ in haze with $\mathrm{MoS}_{2}$ modified electrode, and good results were obtained.
\end{abstract}

\section{Introduction}

The emission of flue gases from the combustion of sulfur-containing fossil fuels causes the environment to be greatly polluted. In recent years, the fog and haze has greatly affected human health, and $\mathrm{SO}_{2}$ is a major pollutant. Therefore, $\mathrm{SO}_{2}$ emissions have to be controlled and minimized in order to reduce environmental risks. It is necessary to separate and concentrate the sulfur dioxide so that it can be recovered and reused in some processes. Room-temperature ionic liquids (RTILs) have great potential to serve as new solvents for a variety of processes because of their unique properties and the ability to customize their properties by changing their substituents. One of their most useful features is their priority ability to absorb certain gases, such as $\mathrm{CO}_{2}[1]$ and $\mathrm{SO}_{2}[2,3]$, and it has near zero vapor pressure and very high stabilities.

As an environment-friendly solvent, the emergence of ionic liquids has found a new way to solve the problem of environmental pollution. The use of ionic liquids for desulfurization has gradually become a research hotspot. Since the first report in 2004, there has been more than 10 years of extensive research on ionic liquids for sulfur dioxide removal [4-6]. But there is few research on ionic liquids both for sulfur dioxide removal and the electrochemistry detection.

In this work, we demonstrated an electrochemical sensor based on $\mathrm{MoS}_{2}$ for the detection of the absorption and desorption of $\mathrm{SO}_{2}$ in ILs. The sensor shows relatively high sensitivity for $\mathrm{SO}_{2}$ due to the good absorption properties of ILs.

\section{Experiment}

\subsection{Materials}

Ionic liquids 1-butyl-3-methylimidazolium bis[(trifluoromethyl)sulfonyl]imide ([Bmim][Tf $\left.{ }_{2} \mathrm{~N}\right]$ was purchased from Centre for greenchemistry and catalysis. The Molybdenum disulfide $\left(\mathrm{MoS}_{2}\right)$ 
dispersions in NMP (N-methyl-2-pyrrolidone) was purchased from Jining LeaderNano Tech L.L.C., and maximum concentration can be up to $40 \mathrm{mg} / \mathrm{L}$. Nafion (5\% in alcohol) were obtained from Sigma-Aldrich. Sulfur powder precipitated was purchased from Alfa Aesar and had a purity of 99.5\%. All reagents and solvents were A. R. grade. Aqueous solutions were prepared with doubly distilled water.

\subsection{Instrumentation}

Electrochemical measurements were performed with a CHI 660D electrochemical workstation (Chenhua Instruments Co., Shanghai, China). The electrochemical cell was assembled with a conventional three-electrode system. A coiled platinum wire was used as a counter electrode. A modified glassy carbon (GC) was used as the working electrode. All potentials are referenced to a sodium saturated calomel electrode (SSCE). The cell was a one compartment cell with an internal volume of $10 \mathrm{~mL}$. The three electrodes were inserted into the cell through holes in its Teflon cover.

\subsection{Preparation of Nafion/ $\mathrm{MoS}_{2} / \mathrm{GC}$}

Preparation of Nafion/GC. A glassy carbon (GC, $3 \mathrm{~mm}$ in diameter, CHI 104) electrode was carefully polished with $1.0,0.3$ and $0.05 \mathrm{~mm}$ alumina slurries, respectively, and rinsed thoroughly with doubly distilled water between each polishing step, then washed successively with $1: 1$ nitric acid, acetone, and doubly distilled water in an ultrasonic bath, and dried in air. Subsequently, $3 \mu \mathrm{L}$ of the $\mathrm{MoS}_{2}$ dispersion was cast onto the surface of the pretreated GC electrode with a microsyringe and the solvent was allowed to dry at ambient temperature. Finally, $3 \mu \mathrm{L}$ of the Nafion $(0.1 \%$ in alcohol) solution was cast onto the $\mathrm{MoS}_{2}$ modified GC electrode and after it dried get the Nafion/MoS $/$ GC electrode.

\subsection{Absorption of $\mathrm{SO}_{2}$}

$3 \mu \mathrm{L}$ of the Nafion $(0.1 \%$ in alcohol) solution was cast onto the carefully polished and washed bare GC electrode and dried the modified electrode before use.

\subsection{Detection methods}

Electrochemical detection was carried out with a three-electrode system using a weighing bottle as an electrolytic cell. All the experimental procedures are carried out under normal atmospheric pressure at $25^{\circ} \mathrm{C}$.

\section{Results and discussion}

\subsection{Characterization of $\mathrm{MoS}_{2}$}

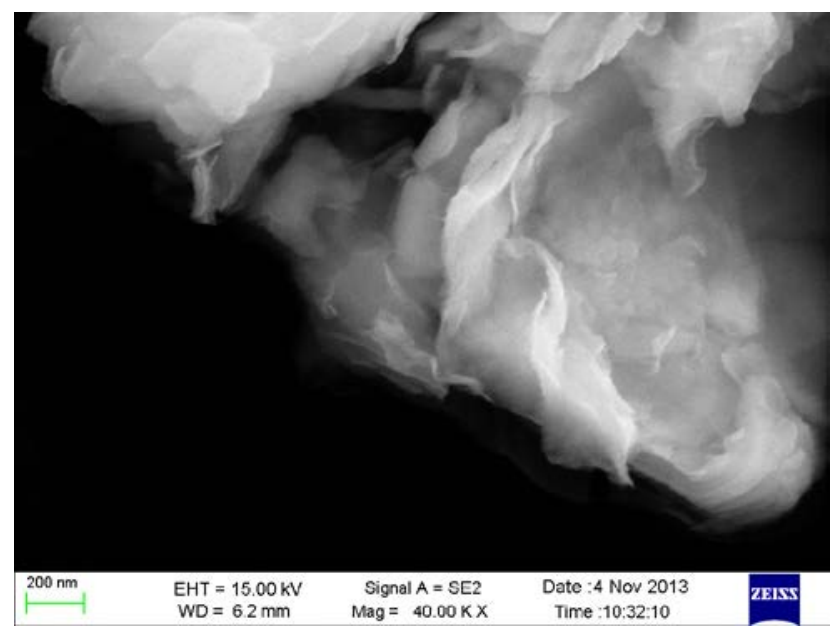

Fig. 1 SEM image of MoS2 nanomaterial.

The nanomaterial sample was examined for morphology by SEM. It can be seen from the scanning 
electron microscopy that $\mathrm{MoS}_{2}$ is basically a multilayer sheet structure, but there is a phenomenon of partial agglomeration. This structure of nanomaterials can greatly increase the contact area with the reactants.

\subsection{Characterization of SO2 absorbed in [Bmim] $\left[\mathrm{Tf}_{2} \mathrm{~N}\right]$}

We compared the CV curves of the pure ILs (b) and $\mathrm{SO}_{2}$-absorbed ILs (a). No obvious peak can be observed in the pure ILs, except for a pair of very small peaks at $-0.8 \mathrm{~V}$ and $-0.75 \mathrm{~V}$, while the peaks were very low compared to the peaks of $\mathrm{SO}_{2}$. The cyclic voltammetric $(\mathrm{CV})$ responses of $0.236 \%$ $\mathrm{SO}_{2}$ in $[\mathrm{Bmim}]\left[\mathrm{Tf}_{2} \mathrm{~N}\right]$ was shown in Fig.2a. In the potential range of -0.5 to $-0.8 \mathrm{~V}$, one can clearly observe a pair of well defined and symmetric redox waves with a peak separation of $0.276 \mathrm{~V}$ and peak current ratio was approached to unit. This indicates that the electrochemical behavior of $\mathrm{SO}_{2}$ absorbed in $[\mathrm{Bmim}]\left[\mathrm{Tf}_{2} \mathrm{~N}\right]$ is a quasi-reversible process.

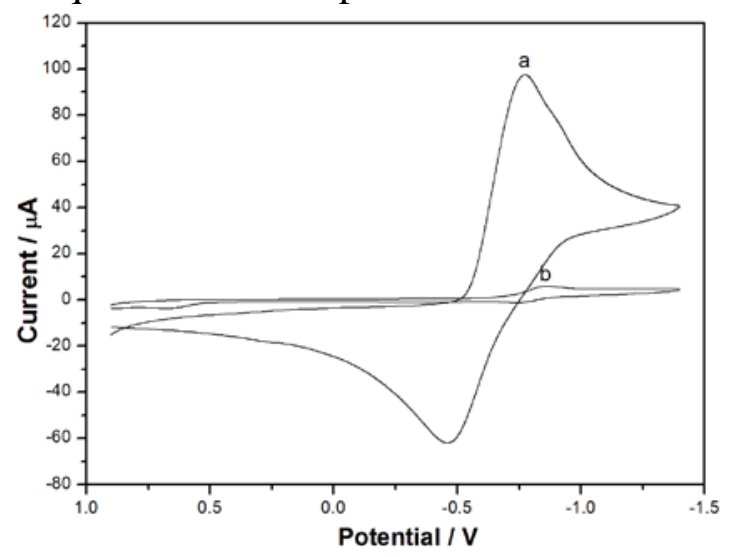

Fig.2 Cyclic voltammetric (CV) responses in $[\mathrm{Bmim}]\left[\mathrm{Tf}_{2} \mathrm{~N}\right]$ absorbed $0.236 \% \mathrm{SO}_{2}$ (a) and pure $[\mathrm{Bmim}]\left[\mathrm{Tf}_{2} \mathrm{~N}\right]$ (b) at Nafion/ $\mathrm{MoS}_{2} / \mathrm{GCE}$. Scan rate: $50 \mathrm{mV} / \mathrm{s}$.

\subsection{Characterization of Nafion/ $\mathrm{MoS}_{2} / \mathrm{GCE}$}

We also compared the electrochemical behavior of $0.236 \% \mathrm{SO}_{2}$ in $[\mathrm{Bmim}]\left[\mathrm{Tf}_{2} \mathrm{~N}\right]$ at three kinds of modified electrodes. We performed control experiments to assess whether the preparation conditions (instead of the $\mathrm{MoS}_{2}$ or Nafion modifiers themselves) have an effect on the catalytic behavior. For this reason, the GC surface was coated with Nafion, which resulted in the lowest redox peaks of $\mathrm{SO}_{2}$ at the Nafion/GC electrode (Figure 4c). The results was lower than that of at GC electrode because of the inhibition of Nafion. Therefore, a well-defined redox peaks observed in the presence of $\mathrm{MoS}_{2}$ (Figure 4a) clearly indicates that the main role of $\mathrm{MoS}_{2}$. The redox peak currents were all enlarged, which may be due to the larger specific surface area of $\mathrm{MoS}_{2}$.

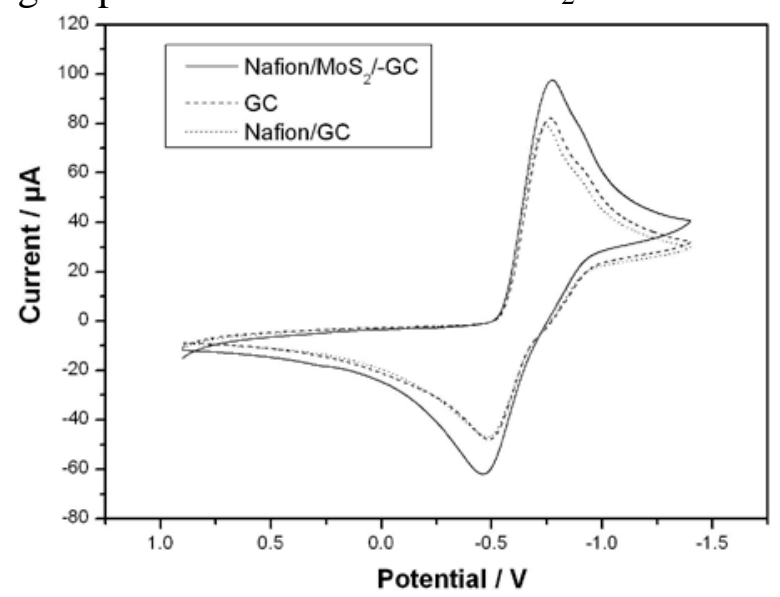

Fig.3 0.236\% $\mathrm{SO}_{2}$ absorbed in [Bmim] $\left[\mathrm{Tf}_{2} \mathrm{~N}\right]$ detected at Nafion/ $\mathrm{MoS}_{2} / \mathrm{GCE}$ compared with GCE and Nafion/GCE. Scan rate: $50 \mathrm{mV} / \mathrm{s}$. 


\subsection{Desorption and reuse of the $[\mathrm{Bmim}]\left[\mathrm{Tf}_{2} \mathrm{~N}\right]$}

In this work, the $\mathrm{SO}_{2}$ absorbed by the $[\mathrm{Bmim}]\left[\mathrm{Tf}_{2} \mathrm{~N}\right]$ was removed mainly under the condition of vacuum heating at $80^{\circ} \mathrm{C}$ for 1 hour. From the results of electrochemical detection before and after desorption (as shown in the Fig.5), it can be clearly seen that the $\mathrm{SO}_{2}$ absorbed in the ionic liquid is almost completely resolved, and the CV diagram after analysis is almost identical to the CV diagram of the blank ionic liquid. This result indicates that the ionic liquid has a good regeneration performance, and the ionic liquid after absorbing $\mathrm{SO}_{2}$ can be regenerated and reused by a simple vacuum heating method. Because the ionic liquids have higher effective absorption capacity and good $\mathrm{SO}_{2}$ enrichment capability, the $\mathrm{SO}_{2}$ absorbed by the ionic liquids can also be used as industrial raw materials for other industrial production.

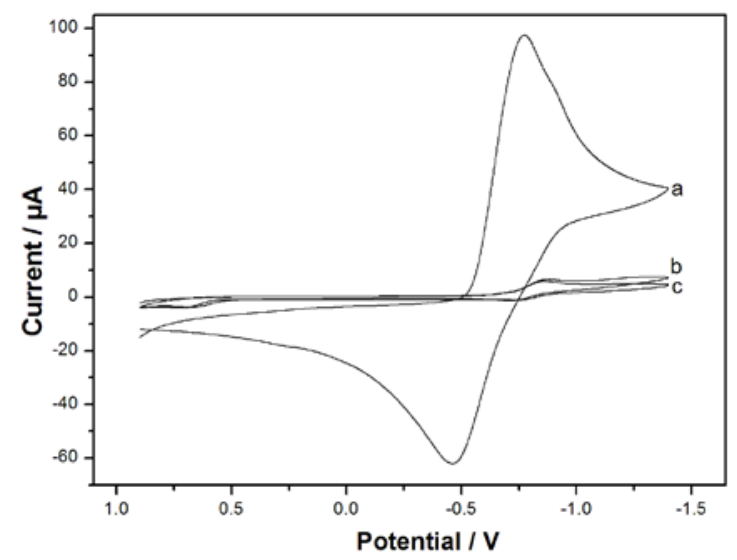

Fig.4 Cyclic voltammetric (CV) responses of $0.236 \% \mathrm{SO}_{2}$ absorbed in [Bmim] $\left[\mathrm{Tf}_{2} \mathrm{~N}\right]$ before (a) and after desorption (b), compared with pure $\left.[\mathrm{Bmim}] \mathrm{Tf}_{2} \mathrm{~N}\right]$ (c). Scan rate: $50 \mathrm{mV} / \mathrm{s}$.

\subsection{Electrochemical detection of $\mathrm{SO}_{2}$ absorbed in [Bmim] $\left[\mathrm{Tf}_{2} \mathrm{~N}\right]$}

In Fig. 5A, it is easily found that the amperometric response increases gradually with increased absorption rate. The cathodic and anodic peak currents both increased, exhibiting the excellent electrocatalytic activity of $\mathrm{MoS}_{2}$ towards the redox of $\mathrm{SO}_{2}$. From Fig. 5B we can see the linear relationship of the absorption rate of $\mathrm{SO}_{2}$ and the anodic peak currents. We found that the correlation coefficient of $\mathrm{SO}_{2}$ in $[\mathrm{Bmim}]\left[\mathrm{Tf}_{2} \mathrm{~N}\right]$ was 0.995 . From the linear relationship we can conclude that Nafion/ $\mathrm{MoS}_{2} / \mathrm{GC}$ electrode has a sensitivity of $564.34 \mu \mathrm{A} / 1 \%$ for $\mathrm{SO}_{2}$ detection. That is, sulfur dioxide absorbed with $[\mathrm{Bmim}]\left[\mathrm{Tf}_{2} \mathrm{~N}\right]$ can be detected with $\mathrm{Nafion} / \mathrm{MoS}_{2} / \mathrm{GC}$ electrode. Therefore, we use this method for the detection of sulfur dioxide in heavily contaminated haze weather.
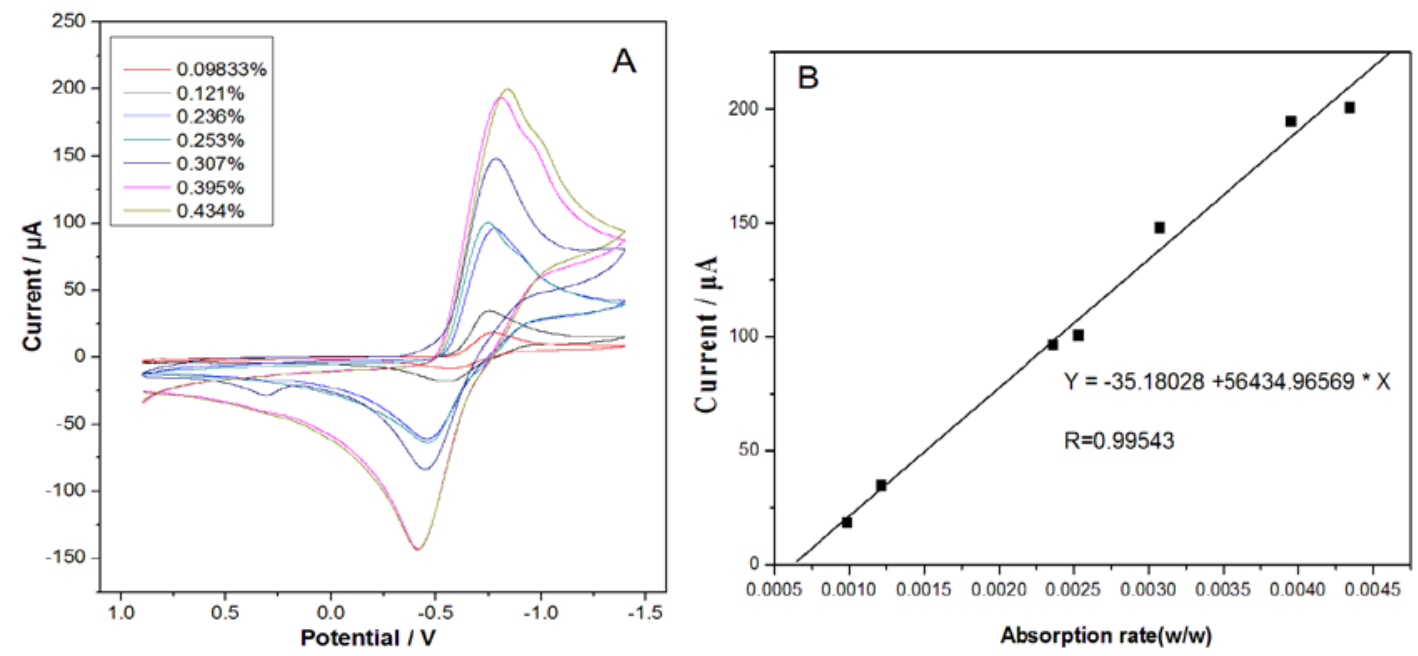

Fig.5 A: Cyclic voltammetric (CV) responses of different absorption rate of $\mathrm{SO}_{2}$ in $[\mathrm{Bmim}]\left[\mathrm{Tf}_{2} \mathrm{~N}\right]$; B: Linear relationship of different absorption rate of $\mathrm{SO}_{2}$ and the peak currents, detected at Nafion/ $\mathrm{MoS}_{2} / \mathrm{GC}$ electrode. Scan rate: $50 \mathrm{mV} / \mathrm{s}$. 
The repeatability and stability of the Nafion/ $\mathrm{MoS}_{2} / \mathrm{GC}$ electrode were tested. Several experiments were performed when $0.121 \% \mathrm{SO}_{2}$ was absorbed in $[\mathrm{Bmim}]\left[\mathrm{Tf}_{2} \mathrm{~N}\right]$ with cyclic voltammetry. The results showed that Nafion/MoS $/$ GC has a very high reproducibility with a relative standard deviation of $3.8 \%$. The stability of the operation was studied within 10 hours and the test was repeated pur hour. The current response only dropped by about $14.6 \%$ over 10 hours, which indicates that the Nafion/ $\mathrm{MoS}_{2} / \mathrm{GC}$ electrode has good operational stability and is sufficient for several hours of continuous use.

\subsection{Detection of $\mathrm{SO}_{2}$ in haze absorbed in [Bmim] $\left[\mathrm{Tf}_{2} \mathrm{~N}\right]$}

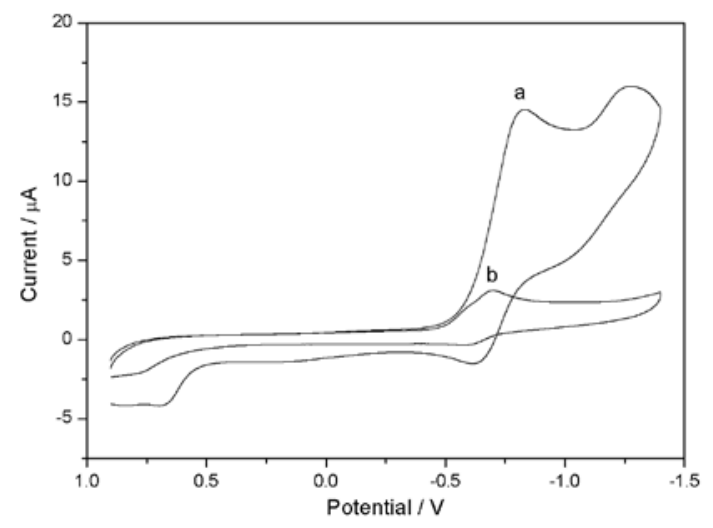

Fig.6 Detection of Haze absorbed in $\left.\left[\mathrm{Bmim}_{[}\right] \mathrm{Tf}_{2} \mathrm{~N}\right](\mathrm{a})$, compared with pure $[\mathrm{Bmim}]\left[\mathrm{Tf}_{2} \mathrm{~N}\right](\mathrm{b})$. Scan rate: $50 \mathrm{mV} / \mathrm{s}$.

Based on the above research, we applied the reported method to detect $\mathrm{SO}_{2}$ in haze. We placed the [Bmim] $\left[\mathrm{Tf}_{2} \mathrm{~N}\right]$ outside in the open to absorb $\mathrm{SO}_{2}$ for 2 hours, and we detected the $\mathrm{SO}_{2}$ using electrochemistry methods and compared the results with the blank ILs. As can be seen from Figure 6, there is one $12.42 \mu \mathrm{A}$ cathode peak at $-0.8 \mathrm{~V}$ and one $1.8 \mu \mathrm{A}$ anode peak at $-0.6 \mathrm{~V}$. Compared with the detection results of blank ionic liquids, both peaks have a greater increase. According to the cathode peak current value and the previously measured linear equation, the amount of $\mathrm{SO}_{2}$ in haze absorbed in the $[\mathrm{Bmim}]\left[\mathrm{Tf}_{2} \mathrm{~N}\right]$ can be calculated to be approximately $0.0843 \%$. This means that $[\mathrm{Bmim}]\left[\mathrm{Tf}_{2} \mathrm{~N}\right]$ can be used to absorb $\mathrm{SO}_{2}$ in haze and can be detected through electrochemical methods using $\mathrm{MoS}_{2}$-modified electrodes.

\section{Summary}

Under normal atmospheric pressure, ionic liquids have a good effect for absorbing $\mathrm{SO}_{2}$. The [Bmim] $\left[\mathrm{Tf}_{2} \mathrm{~N}\right]$ that absorbed $\mathrm{SO}_{2}$ was directly used as an electrolyte for measuring the $\mathrm{SO}_{2}$ absorption rate and very good results were obtained. By comparing the redox reactions of $\mathrm{SO}_{2}$ with three kinds of electrodes, it was found that the reaction current was highest, indicating that $\mathrm{MoS}_{2}$ has better electrochemical properties. We got good results with ionic liquids to absorb $\mathrm{SO}_{2}$ in haze and using $\mathrm{MoS}_{2}$ modified electrode for detection. It is showed that the method of this paper has certain potential applications.

\section{Acknowledgement}

The authors are profoundly grateful for the financial support provided by Natural Science Foundation of Shandong province (No. ZR2016BP10, No. ZR2017BB015, No. ZR2013HL011) and the Youth Support Foundation of Jining Medical University (No. JY2016KJ035Y).

\section{References}

[1] J. Huang, T. Rüther, why are Ionic Liquids Attractive for CO2 Absorption? An Overview, Aust. J. Chem. 62 (2009) 298-308. 
[2] K. Y. Lee, Chang Soo Kim, Honggon Kim, Effects of Halide Anions to Absorb SO2 in Ionic Liquids, B. Korean Chem. Soc. 31 (2010) 1937-1940.

[3] S. Ren, Y. Hou, W. Wu, Properties of Ionic Liquids Absorbing SO2 and the Mechanism of the Absorption, J. Phys. Chem. B 114 (2010) 2175-2179.

[4] C. Wang, G. Cui, X. Luo, Y. Xu, H. Li, S. Dai, Highly Efficient and Reversible SO2 Capture by Tunable Azole-Based Ionic Liquids through Multiple-Site Chemical Absorption, J. Am. Chem. Soc vol. 133, pp. 11916-11919, 2011.

[5] P. Luis, L.A. Neves, C.A.M. Afonso, I.M. Coelhoso, J.G. Crespo, A. Garea, A. Irabien, Facilitated transport of CO2 and SO2 through Supported Ionic Liquid Membranes (SILMs), Desalination vol. 245, pp. 485-493, 2009.

[6] C. D. Wick, T. Chang, L. X. Dang, Molecular Mechanism of CO2 and SO2 Molecules Binding to the Air / Liquid Interface of 1-Butyl-3-methylimidazolium Tetrafluoroborate Ionic Liquid: A Molecular Dynamics Study with Polarizable Potential Models, J. Phys. Chem. B vol. 114, pp. 14965-14971, 2010. 